\title{
Effect of amino acid infusion on potassium serum levels in neuroendocrine tumour patients treated with targeted radiopeptide therapy
}

\author{
Giampiero Giovacchini • Guillaume Nicolas • \\ Heike Freidank • Thomas L. Mindt • Flavio Forrer
}

Received: 23 December 2010/Accepted: 8 April 2011 /Published online: 7 May 2011

(C) Springer-Verlag 2011

\begin{abstract}
Purpose Administration of positively charged amino acids has been introduced to reduce the nephrotoxicity of targeted radiopeptide therapy (TRT). However, the amino acid solution may have side effects, including hyperkalaemia. The aim of this study was to evaluate the frequency and the magnitude of hyperkalaemia in neuroendocrine tumour (NET) patients undergoing TRT.

Methods Enrolled in the study were 31 patients with NET eligible for TRT with $\left[{ }^{90} \mathrm{Y}\right.$-DOTA(0), Tyr(3)]octreotide $\left({ }^{90} \mathrm{Y}\right.$ DOTATOC). Their mean age was $54 \pm 14$ years. Of these 31 patients, $21(67 \%)$ were referred for the first treatment cycle, while $10(33 \%)$ were referred for a subsequent therapy cycle. Patients were treated with therapeutic doses of ${ }^{90}$ Y-DOTATOC ranging from 7,030 to $35,520 \mathrm{MBq}$. To inhibit tubular reabsorption of ${ }^{90}$ Y-DOTATOC, 11 of physiological saline solution containing $25 \mathrm{~g}$ of arginine hydrochloride and $25 \mathrm{~g}$ of lysine hydrochloride was given over $4 \mathrm{~h}$ starting $1 \mathrm{~h}$ before ${ }^{90}$ Y-DOTATOC injection. All patients underwent a standard biochemical blood analysis at baseline, and $4 \mathrm{~h}$ and $24 \mathrm{~h}$ after the beginning of the amino acid infusion.
\end{abstract}

\section{G. Giovacchini $(\triangle) \cdot$ G. Nicolas $\cdot$ F. Forrer}

Department of Radiology and Nuclear Medicine,

Division of Endocrine Diagnostics and Radionuclide Therapy,

University Hospital Basel,

4031, Basel, Switzerland

e-mail: giovacchinig@uhbs.ch

H. Freidank

Laboratory Medicine, University Hospital Basel,

Basel, Switzerland

T. L. Mindt

Division of Radiological Chemistry, University Hospital Basel,

Basel, Switzerland
Results ANOVA repeated measures showed a significant overall effect on $\mathrm{K}^{+}$levels over time $(F=118.2, \mathrm{df}=2, P<$ $0.0001)$. Mean serum levels of $\mathrm{K}^{+}$were $4.00 \pm 0.33 \mathrm{mmol} /$ 1 at baseline, $5.47 \pm 0.57 \mathrm{mmol} / \mathrm{l}$ at $4 \mathrm{~h}$, and $4.38 \pm$ $0.63 \mathrm{mmol} / \mathrm{l}$ at $24 \mathrm{~h}$ after the beginning of the infusion. Post-hoc analysis showed that $\mathrm{K}^{+}$levels at $4 \mathrm{~h}$ were significantly $(P<0.05)$ higher than at baseline. $\mathrm{K}^{+}$levels at $24 \mathrm{~h}$ were significantly $(P<0.05)$ lower than at $4 \mathrm{~h}$ but they were still significantly $(P<0.05)$ higher than $\mathrm{K}^{+}$levels at baseline. On a subject-by-subject basis, none of the 31 patients had increased $\mathrm{K}^{+}$levels at baseline. At $4 \mathrm{~h}, 24$ of the 31 patients $(77 \%)$ had $\mathrm{K}^{+}$levels above the normal range, and 6 patients (19\%) experienced severe hyperkalaemia $\left(\mathrm{K}^{+} \geq 6 \mathrm{mmol} / \mathrm{l}\right)$. All patients with increased $\mathrm{K}^{+}$ levels were clinically asymptomatic. At $24 \mathrm{~h}$, only 4 patients $(13 \%)$ had increased $\mathrm{K}^{+}$serum levels. The magnitude of the increase in $\mathrm{K}^{+}$levels between baseline and $4 \mathrm{~h}$ was relatively homogeneous over the whole group $(1.41 \pm 0.50 \mathrm{mmol} / \mathrm{l})$ and it was not related (linear regression, $P>0.05)$ to baseline $\mathrm{K}^{+}$levels. Intravenous administration of $40 \mathrm{mg}$ furosemide $1 \mathrm{~h}$ after the beginning of the amino acid infusion did not have a significant effect on $\mathrm{K}^{+}$levels $(P>0.05)$. No clinical characteristic was predictive for the increase in $\mathrm{K}^{+}$levels (chi-squared test, $P>0.05)$.

Conclusion Hyperkalaemia is a frequent, potentially lifethreatening side effect of basic amino acid infusion during TRT. $\mathrm{K}^{+}$levels $4 \mathrm{~h}$ after the beginning of the infusion should be monitored in patients at risk of complications, such as those with heart disease and those with risk factors for nephrotoxicity.

Keywords Neuroendocrine tumours · Hyperkalaemia · Targeted radiopeptide therapy. ${ }^{90}$ Y-DOTATOC 


\section{Introduction}

Targeted radiopeptide therapy (TRT) is an effective therapeutic approach for patients with neuroendocrine tumour (NET) who are no longer eligible for surgery [1]. This therapy relies on the use of radiolabelled peptides that preferentially bind to the somatostatin receptor $2\left(\mathrm{SST}_{2}\right)$. Following binding, the peptide-receptor complex is rapidly internalized, and the radioactive peptide is trapped in the cell and produces cytotoxic damage [2].

Bone marrow toxicity and kidney toxicity are generally dose-limiting factors of TRT [3-6]. Renal uptake of radiolabelled somatostatin (SST) analogues occurs in the proximal tubule cells and largely depends on the multiligand megalin/cubulin system [7]. The receptor involved in the renal uptake of radioactive peptides binds various structurally different proteins, including albumin and $\beta_{2}$ microglobulin [8]. Basic amino acids, including arginine and lysine, bind to megalin via their cationic sites and therefore competitively inhibit renal reabsorption of radioactive peptide used in TRT [813]. The reduction in renal uptake induced by cationic amino acids ranges between $15 \%$ and $60 \%$ depending on the amount of amino acids being used and on the experimental design [9-13]. However, amino acid solutions may have some disadvantages. For examples, they can induce nausea and vomiting, hyperosmolarity and hyperkalaemia, and at high doses they may themselves induce nephrotoxicity $[12,14]$. Among these side effects, hyperkalaemia may be particularly dangerous because it is associated with a high risk of cardiac arrhythmias [1517]. This is particularly true in patients with preexisting heart disease. The aim of this prospective study was to assess the effect of amino acid solutions on serum potassium $\left(\mathrm{K}^{+}\right)$concentrations in patients with NET undergoing TRT with $\left[{ }^{90} \mathrm{Y}\right.$-DOTA(0), Tyr(3)]octreotide $\left({ }^{90} \mathrm{Y}\right.$-DOTATOC $)$.

\section{Patients and methods}

\section{Patients}

The study included 31 patients with NET eligible for TRT. Their mean age was $54 \pm 14$ years. The clinical characteristics of the patients are summarized in Table 1. Disease was confirmed in all patients by histology. Overexpression of $\mathrm{SST}_{2}$ was documented prior to TRT by $\left[{ }^{111} \mathrm{In}_{-} \mathrm{DTPA}^{0}\right]$ octreotide scintigraphy or PET/CT using ${ }^{68} \mathrm{Ga}$-labelled SST analogues. In all patients the use of long acting SST analogues had been withdrawn for at least 6 weeks prior to TRT and short-acting SST analogues had been withdrawn for at least 3 days prior to TRT.
Exclusion criteria were: (a) pregnancy or lactation; (b) age $<21$ years; (c) Karnofsky performance status $<60$ and life expectancy $<6$ months; (d) white blood cell count $<2 \times$ $10^{9} / 1$; (e) haemoglobin $<80 \mathrm{~g} / \mathrm{l}$; (f) platelets $<100 \times 10^{9} / 1$, and $(\mathrm{g})$ increased creatinine levels. Written informed consent was obtained from all patients. The study was approved by the local ethics committee.

\section{Radiopharmaceuticals}

${ }^{90}$ Y-DOTATOC was synthesized in-house according to a previously published procedure $[18,19] .{ }^{90} \mathrm{Y}$ was purchased from Perkin Elmer (USA) and ${ }^{111}$ In was purchased from Tyco Healthcare (Petten, The Netherlands). The final radiopharmaceutical was analysed by thin-layer chromatography (Biodex) using a phosphor imager (Cyclone Plus, Perkin Elmer) and reverse-phase high-performance liquid chromatography (Bischoff) using a Chromolith column (Merck) and a $\gamma$-detector (Berthold) [19]. The radiolabelling yield and radiochemical purity of ${ }^{90} \mathrm{Y}$ - and ${ }^{111}$ In-DOTATOC were higher than $99.5 \%$.

\section{TRT}

Patients were hospitalized for 3 days in accordance with the legal requirements for radioactivity protection. Of the 31 patients included, $21(67 \%)$ were referred for the first treatment cycle, and $10(33 \%)$ were referred for a subsequent therapy cycle.

To inhibit tubular reabsorption of ${ }^{90}$ Y-DOTATOC, 11 of physiological solution containing $25 \mathrm{~g}$ of arginine hydrochloride and $25 \mathrm{~g}$ of lysine hydrochloride was given $1 \mathrm{~h}$ before TRT. The infusion pump was set to $250 \mathrm{ml} /$ $\mathrm{h}$ starting $1 \mathrm{~h}$ before ${ }^{90} \mathrm{Y}$-DOTATOC injection for a total infusion time of $4 \mathrm{~h}$. In each therapy session, $111 \mathrm{MBq}$ of ${ }^{111}$ In-DOTATOC was coinjected with ${ }^{90} \mathrm{Y}$-DOTATOC to allow scintigraphic imaging. The therapeutic cumulative radioactivity doses ranged from 7,030 to $35,520 \mathrm{MBq}$ of ${ }^{90} \mathrm{Y}$-DOTATOC. All patients were symptomatic or had progressive disease. The following risk factors for the development of kidney toxicity were identified: arterial hypertension, diabetes, renal morphological abnormalities, history of use of radiological contrast medium and history of chemotherapy with nephrotoxic agents [4].

Measurement of $\mathrm{K}^{+}$levels and blood radioactivity

All patients underwent a standard baseline haematological and biochemical analysis of blood. The biochemical analysis was repeated $4 \mathrm{~h}$ and $24 \mathrm{~h}$ after the beginning of the amino acid infusion. No tourniquet was applied while drawing blood samples to avoid potential bias in the measurement of $\mathrm{K}^{+}$levels. Since the primary aim of this 
Table 1 Clinical characteristics of the patients

\begin{tabular}{|c|c|c|c|c|c|}
\hline Patient no. & Sex & Age (years) & Primary tumour & Documented lesions & Previous therapies \\
\hline 1 & $\mathrm{~F}$ & 61 & Small-bowel NET & Liver, lymph nodes & SST analogues, transarterial chemoembolization \\
\hline 2 & $\mathrm{~F}$ & 46 & Paraganglioma & Liver, lymph nodes, bone & Surgery, SST analogues \\
\hline 3 & $\mathrm{~F}$ & 59 & NET of unknown origin & Liver, lymph nodes & SST analogues \\
\hline 4 & $\mathrm{~F}$ & 60 & NET of unknown origin & Liver, bone & SST analogues \\
\hline 5 & M & 61 & Pancreatic NET & Liver, bone & Surgery \\
\hline 6 & $\mathrm{~F}$ & 36 & NET of unknown origin & Liver, bone & SST analogues, chemotherapy \\
\hline 7 & $\mathrm{~F}$ & 45 & Pancreatic NET & Liver & SST analogues \\
\hline 8 & M & 26 & NET of unknown origin & Liver, bone & SST analogues, chemotherapy \\
\hline 9 & $\mathrm{~F}$ & 38 & Pancreatic NET & Liver & SST analogues \\
\hline 10 & $\mathrm{~F}$ & 77 & Pancreatic NET & Liver, bone & Surgery \\
\hline 11 & $\mathrm{~F}$ & 18 & Pancreatic NET & Liver & SST analogues \\
\hline 12 & $\mathrm{~F}$ & 52 & Meningioma & Local relapse & Gamma knife \\
\hline 13 & M & 39 & Small-bowel NET & Liver, lymph nodes & SST analogues \\
\hline 14 & $\mathrm{~F}$ & 52 & Lung carcinoid & Local relapse & Surgery \\
\hline 15 & $\mathrm{~F}$ & 57 & Paraganglioma & Local relapse & None \\
\hline 16 & $\mathrm{~F}$ & 68 & NET of unknown origin & Liver & SST analogues \\
\hline 17 & M & 58 & Rectal NET & Liver, lymph nodes & Surgery, transarterial chemoembolization \\
\hline 18 & M & 50 & Pancreatic NET & Liver & SST analogues \\
\hline 19 & $\mathrm{~F}$ & 51 & Pancreatic NET & Liver & SST analogues \\
\hline 20 & M & 50 & Pancreatic NET & Liver bone & SST analogues \\
\hline 21 & M & 65 & Pancreatic NET & Liver & SST analogues, chemotherapy \\
\hline 22 & $\mathrm{~F}$ & 72 & Pancreatic NET & Liver, lymph nodes & Surgery, SST analogues \\
\hline 23 & $\mathrm{~F}$ & 60 & Pancreatic NET & Liver, bone & SST analogues \\
\hline 24 & $\mathrm{~F}$ & 41 & Pancreatic NET & Liver & None \\
\hline 25 & M & 80 & NET of unknown origin & Liver & None \\
\hline 26 & M & 57 & Pancreatic NET & Liver & Surgery, SST analogues, chemotherapy \\
\hline 27 & $\mathrm{~F}$ & 68 & Pancreatic NET & Liver, bone & Chemotherapy \\
\hline 28 & M & 59 & Small-bowel NET & Liver, lymph node & Surgery \\
\hline 29 & $\mathrm{~F}$ & 54 & Pancreatic NET & Liver & SST analogues, chemotherapy, interferon \\
\hline 30 & $\mathrm{~F}$ & 51 & Gastric NET & Liver & Surgery, SST analogues \\
\hline 31 & M & 56 & Lung carcinoid & Liver, lymph node & Surgery, SST analogues \\
\hline
\end{tabular}

study was to assess the effect of amino acid solution on $\mathrm{K}^{+}$ levels, the haematological evaluation was not repeated after TRT. Additionally, we assessed the feasibility of preventing the amino acid-induced increase in $\mathrm{K}^{+}$serum levels in 19 patients who underwent a subsequent TRT after 1012 weeks. For this aim, we administered $40 \mathrm{mg}$ furosemide i.v. $5 \mathrm{~min}$ before the second ${ }^{90} \mathrm{Y}$-DOTATOC injection. The dose of furosemide was chosen on the basis of a previous study in humans indicating that kaliuresis following i.v. injection of $40 \mathrm{mg}$ furosemide peaks $30 \mathrm{~min}$ after the injection and returns to baseline by $3.5 \mathrm{~h}$ [20].

Blood samples $(4-5 \mathrm{ml})$ were collected into lithium heparin gel tubes (S-Monovette). Within $30 \mathrm{~min}$ of blood withdrawal, all blood samples were centrifuged at 3,000 rpm (1,830 $\mathrm{g}$; Multicentrifuge $3 \mathrm{SR}+$, Thermo Scientific) for $5 \mathrm{~min}$ in the C-laboratories of the Nuclear
Medicine Department. After centrifugation, the baseline sample was directly sent to the central hospital laboratory for biochemical and haematological analysis. $\mathrm{K}^{+}$levels were measured by potentiometric determination using an ion-selective electrode (ISE 900, Modular; Roche). Normal $\mathrm{K}^{+}$values ranged from 3.7 to $4.7 \mathrm{mmol} / \mathrm{l}$ (Table 1). Samples of serum $(400 \mu \mathrm{l})$ were used for $\mathrm{K}^{+}$measurements (test volume $65 \mu \mathrm{l}$ ). Other analytes were measured according to standard methods.

The radioactive samples taken at $4 \mathrm{~h}$ and $24 \mathrm{~h}$ after the beginning of the infusion were stored for $48 \mathrm{~h}$ in a refrigerator at $4{ }^{\circ} \mathrm{C}$ to allow for radioactivity decay. This procedure became necessary because we had a priori no information on whether the activity levels in blood samples were within safety limits for handling outside the $\mathrm{C}$ laboratories of the Nuclear Medicine Department. Accord- 
ing to the recommendations of the International Commission on Radiological Protection (ICRP) [21] the hand dose limit for non-occupationally exposed persons, as it applies to the personnel of the central hospital laboratory, is $50 \mathrm{mSv} /$ year. The Swiss authorization limit for ${ }^{90} \mathrm{Y}$ under which radioactive blood samples can be processed in nonspecialized laboratories is $3 \mathrm{MBq}$.

Dose-rate (microsieverts per hour) measurements of whole-blood samples (4-5 ml) obtained $4 \mathrm{~h}$ and $24 \mathrm{~h}$ after the beginning of the infusion were determined directly in the sample tube with a dose-rate detector (Berthold LB 133/LB 6006). The amount of radioactivity (megabecquerels) was measured in $50 \mu \mathrm{l}$ of the serum which was mixed with $10 \mathrm{ml}$ scintillation liquid (Ultima Gold, Perkin Elmer) and analysed in duplicate in a $\beta$ counter (1500 Tri-Carb, Packard). To extrapolate the level of radioactivity in the samples at $4 \mathrm{~h}$ and $24 \mathrm{~h}$ after the beginning of the infusion, the measured values were corrected for radioactive decay and scaled to a volume of $400 \mu \mathrm{l}$. After verification that neither a C-laboratory was required nor the hand dose limit had been exceeded, the 4-h and 24-h blood samples were also sent to the central hospital laboratory for biochemical analysis.

\section{Statistics}

Differences between $\mathrm{K}^{+}$levels at baseline, and $4 \mathrm{~h}$ and $24 \mathrm{~h}$ after the beginning of the infusion of the amino acid solution were assessed by ANOVA repeated measures using $\mathrm{K}^{+}$serum levels as repeated factor. Post-hoc tests were performed with Student's $t$-test. The relationship between the number of patients developing hyperkalaemia and clinical characteristics of the study group was evaluated with the chi-squared test. Statistical significance was set at $P<0.05$.

\section{Results}

ANOVA repeated measures showed a significant overall effect on $\mathrm{K}^{+}$levels over time $(F=118.2, \mathrm{df}=2, P<$ $0.0001)$. Mean serum levels of $\mathrm{K}^{+}$were $4.00 \pm$ $0.33 \mathrm{mmol} / 1$ at baseline, $5.47 \pm 0.57 \mathrm{mmol} / 1$ at $4 \mathrm{~h}$, and $4.38 \pm 0.63 \mathrm{mmol} / \mathrm{L}$ at $24 \mathrm{~h}$. Post-hoc analysis showed that $\mathrm{K}^{+}$levels at $4 \mathrm{~h}$ were significantly $(P<0.05)$ higher than at baseline. $\mathrm{K}^{+}$levels at $24 \mathrm{~h}$ were significantly lower than at $4 \mathrm{~h}$, but they were still significantly higher than $\mathrm{K}^{+}$levels at baseline (Fig. 1).

On a subject-by-subject basis, none of the 31 patients had increased $\mathrm{K}^{+}$levels at baseline. At $4 \mathrm{~h}, 24$ of the 31 patients $(77 \%)$ had $\mathrm{K}^{+}$levels above the normal range, and 6 (19\%) showed several hyperkalaemia $\left(\mathrm{K}^{+} \geq 6 \mathrm{mmol} / \mathrm{l}\right)$. The highest $\mathrm{K}^{+}$level was $6.7 \mathrm{mmol} / \mathrm{l}$. At $24 \mathrm{~h}$, only 4 patients

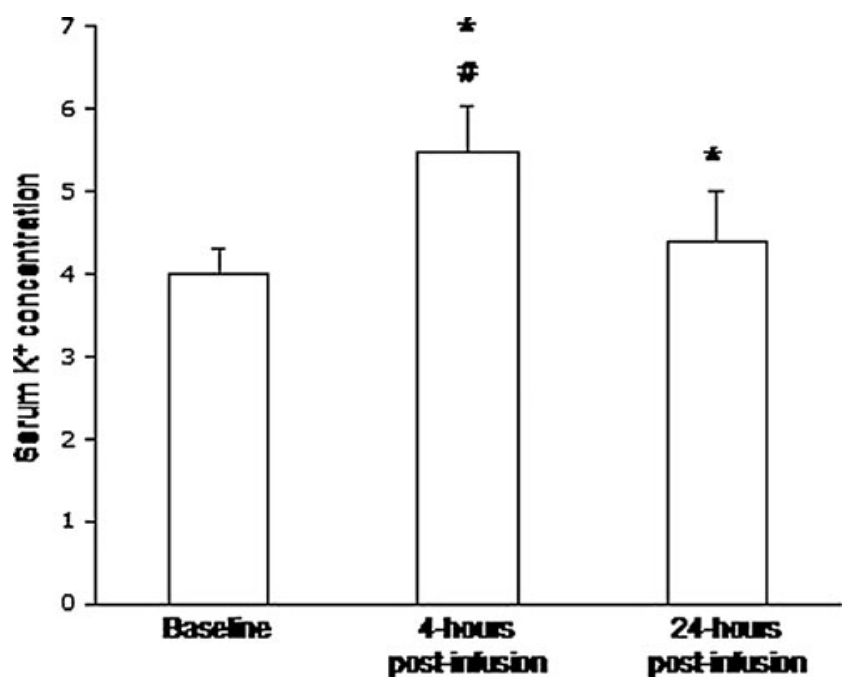

Fig. 1 Serum $\mathrm{K}^{+}$concentrations (millimoles per litre) at baseline, and at $4 \mathrm{~h}$ and $24 \mathrm{~h}$ after the beginning of the infusion of the amino acid solution (4-hours post-infusion, 24-hours post-infusion). ${ }^{*} P<0.05$ in comparison to baseline; ${ }^{\#} P<0.05$ in comparison to 24 -hours

$(13 \%)$ had $\mathrm{K}^{+}$serum levels above the normal range. No patient reported palpitations.

The magnitude of the increase in $\mathrm{K}^{+}$serum levels between baseline and $4 \mathrm{~h}$ was relatively homogeneous in the whole group $(1.41 \pm 0.50 \mathrm{mmol} / \mathrm{l})$ and it was not related to baseline $\mathrm{K}^{+}$levels $(P>0.05$; Fig. 2$)$.

The numbers of patients who developed hyperkalaemia did not differ between those undergoing the first therapy cycle and those undergoing subsequent therapy cycles ( $90 \%$ and $71 \%$ of patients, respectively; $P=0.25$ ), between those who received less and those who received more than the median dose of $12,950 \mathrm{MBq}(71 \%$ and $86 \%$ of patients, respectively; $P=0.29$ ), between those with and those without clinical risk factors for nephrotoxicity $(83 \%$ and

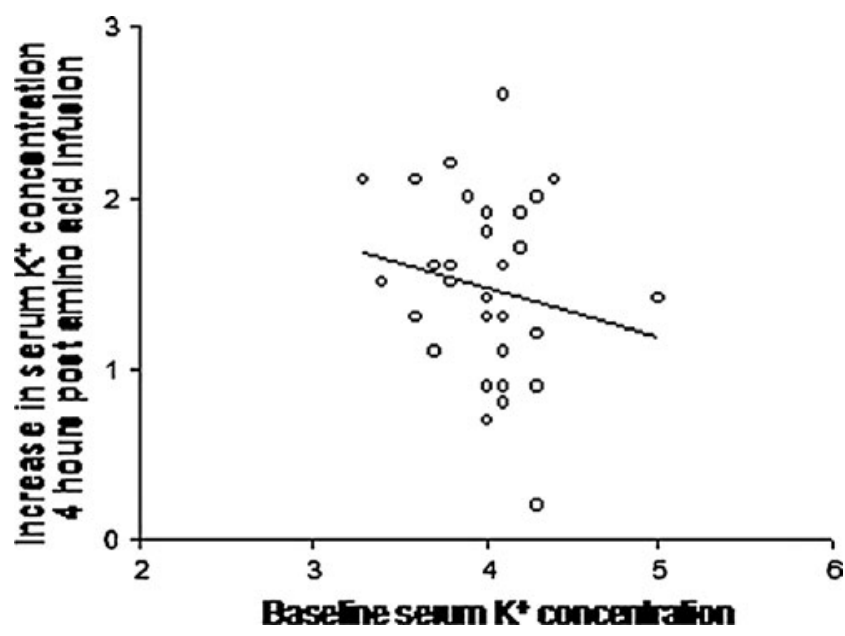

Fig. 2 Increase in $\mathrm{K}^{+}$serum levels at $4 \mathrm{~h}$ after the beginning of the infusion in relation to the baseline $\mathrm{K}^{+}$serum levels. The equation of the line is: $Y=-0.279 X+2.59, r^{2}=0.03 ; P=0.35$ 
$74 \%$ of patients, respectively; $P=0.43$ ), or between those younger and those older than the median age (56 years; $81 \%$ and $73 \%$ of patients, respectively; $P=0.68$ ).

In 19 patients who had $\mathrm{K}^{+}$measurements after furosemide injection, $\mathrm{K}^{+}$serum levels $4 \mathrm{~h}$ after the beginning of the infusion were significantly higher than baseline $(5.17 \pm 0.74$ vs. $3.88 \pm 0.45 \mathrm{mmol} / \mathrm{l} ; P<0.05)$. There was no significant $(P>0.05$, paired $t$-test) difference between the 4-h $\mathrm{K}^{+}$value after furosemide injection and the corresponding 4 -h value $(5.36 \pm 0.41 \mathrm{mmol} / \mathrm{L})$ without furosemide administration. Serum $\mathrm{K}^{+}$levels $24 \mathrm{~h}$ after the beginning of the infusion $(4.18 \pm 0.41 \mathrm{mmol} / \mathrm{l})$ were still significantly $(P<0.05)$ higher than at baseline. On a subject-by-subject basis 13 of the 19 patients (68\%) experienced hyperkalaemia $4 \mathrm{~h}$ after the beginning of the infusion. This value was not significantly different $(P>$ 0.05 , chi-squared test) from the percentage of patients who experienced hyperkalaemia in the absence of furosemide administration.

Radioactivity levels in the volume of serum required for $\mathrm{K}^{+}$analysis $(400 \mu \mathrm{l})$ were $13.3-79.0 \mathrm{kBq}$ (mean value $38.0 \mathrm{kBq}$ ) and $0.5-10.8 \mathrm{kBq}$ (mean value $3.3 \mathrm{kBq}$ ) in samples obtained at $4 \mathrm{~h}$ and $24 \mathrm{~h}$ after the beginning of the infusion, respectively $(n=15)$. These values correspond to about $10 \%$ and $1 \%$ of the injected dose at $4 \mathrm{~h}$ and $24 \mathrm{~h}$, respectively, and are in good agreement with previously reported data on the excretion rate of ${ }^{90}$ Y-DOTATOC [19]. Measurement of whole blood $(4-5 \mathrm{ml} ; n=10)$ at $4 \mathrm{~h}$ gave a dose-rate of $140-400 \mu \mathrm{Sv} / \mathrm{h}$ (mean value $248 \mu \mathrm{Sv} / \mathrm{h}$ ). The effects of the amino acid infusion on other biochemical variables are summarized in Table 2.

\section{Discussion}

Under normal conditions $95 \%$ of $\mathrm{K}^{+}$is found within the cells, while the remaining $5 \%$ is in the blood. This concentration gradient is maintained by the $\mathrm{Na}^{+} / \mathrm{K}^{+}$ATPase pump and is regulated by endocrine as well as nonendocrine factors [22]. The kidney is responsible for maintaining normal $\mathrm{K}^{+}$balance. The renal elimination of $\mathrm{K}^{+}$is passive (through the glomerulus), and reabsorption is active in the proximal tubule and the ascending limb of the loop of Henle. There is active excretion of potassium in the distal tubule and the collecting duct; both are controlled by aldosterone. Of the usual dietary intake of $\mathrm{K}^{+}, 90 \%$ is excreted by the kidney, and the remaining $10 \%$ is excreted in the stool [23].

Several drugs may induce hyperkalaemia. Three mechanisms can be distinguished: (1) increased $\mathrm{K}^{+}$input (i.e. potassium chloride supplements); (2) decreased $\mathrm{K}^{+}$output (i.e. $\mathrm{K}^{+}$-sparing diuretics); (3) induction of a shift of $\mathrm{K}^{+}$ from cells to the extracellular compartment. Arginine monohydrochloride and lysine monohydrochloride induce hyperkalaemia according to the third mechanism $[10,12$, $24,25]$. The ability to drive $\mathrm{K}^{+}$out of the cell is a property of all cationic amino acids, and has been demonstrated in vitro [24] and in vivo [25]. The shift of $\mathrm{K}^{+}$from cells to the extracellular compartment is proportional to the serum levels of the amino acid. In turn, this shift increases renal $\mathrm{K}^{+}$excretion [25]. This may explain the fact that the increase in $\mathrm{K}^{+}$concentration after amino acid infusion during TRT is typically transient (Fig. 1).

The increase in $\mathrm{K}^{+}$levels after amino acid infusion was relatively homogeneous in the whole group and it was not related to baseline $\mathrm{K}^{+}$levels. Increased $\mathrm{K}^{+}$levels were detected in $77 \%$ of patients in our study group, and $19 \%$ of patients had severe hyperkalaemia. These results are unexpectedly high, given that the changes in $\mathrm{K}^{+}$concentration induced by amino acid solution have been generally considered mild [10, 12, 26]. Rolleman et al. assessed the effect of different preparations of amino acid solutions on kidney radioactivity uptake as well as on $\mathrm{K}^{+}$levels. Serum $\mathrm{K}^{+}$levels significantly increased from $4.2 \pm 0.5$ to $5.1 \pm$ $0.6 \mathrm{mmol} / \mathrm{l}$ after administration of $25 \mathrm{mg}$ lysine and $25 \mathrm{mg}$ arginine [12]. The percentage of patients with increased $\mathrm{K}^{+}$ levels was not reported. Barone et al. studied the effect of different amino acid solutions on a variety of chemical parameters [10]. They found increased $\mathrm{K}^{+}$serum levels in patients treated with $50 \mathrm{~g}$ lysine, as well as in patients
Table 2 Biochemical results at baseline, and at $4 \mathrm{~h}$ and $24 \mathrm{~h}$ after the beginning of the amino acid infusion. Values are means \pm SD

$* P<0.05$ compared to baseline;

${ }^{\#} P<0.05$ compared to 24 -hours.

\begin{tabular}{lllll}
\hline & Normal range & Baseline & $4 \mathrm{~h}$ & $24 \mathrm{~h}$ \\
\hline $\mathrm{K}^{+}(\mathrm{mmol} / \mathrm{l})$ & $3.7-4.7$ & $4.00 \pm 0.33$ & $5.47 \pm 0.57^{* \#}$ & $4.38 \pm 0.63^{*}$ \\
$\mathrm{Na}^{+}(\mathrm{mmol} / \mathrm{l})$ & $131-142$ & $138.8 \pm 3.3$ & $134.9 \pm 5^{*}$ & $138.6 \pm 2.6$ \\
$\mathrm{Cl}^{-}(\mathrm{mmol} / \mathrm{l})$ & $97-110$ & $101.5 \pm 3.8$ & $107.7 \pm 6.6^{* \#}$ & $103.6 \pm 3.2^{*}$ \\
Phosphate $(\mathrm{mmol} / \mathrm{l})$ & $0.80-1.50$ & $1.04 \pm 0.20$ & $0.76 \pm 0.24^{* \#}$ & $1.20 \pm 0.21^{*}$ \\
Urea $(\mathrm{mmol} / \mathrm{l})$ & $3.0-7.8$ & $5.7 \pm 2.2$ & $7.7 \pm 2.3^{* \#}$ & $7.2 \pm 2.3^{*}$ \\
Creatinine $(\mu \mathrm{mol} / \mathrm{l})$ & $45-93$ & $65.4 \pm 26.1$ & $67.2 \pm 20.7$ & $64.4 \pm 16.5$ \\
Uric acid $(\mu \mathrm{mol} / \mathrm{l})$ & $173-359$ & $301.2 \pm 87.7$ & $259.0 \pm 80.3^{* \#}$ & $272.9 \pm 70.4^{*}$ \\
Lactate dehydrogenase $(\mathrm{U} / \mathrm{l})$ & $135-214$ & $234.3 \pm 111.5$ & $217.4 \pm 110.7^{*}$ & $227.5 \pm 123.2$ \\
Creatine kinase $(\mathrm{U} / \mathrm{l})$ & $38-157$ & $103.2 \pm 67.9$ & $74.5 \pm 37.3$ & $68.8 \pm 53.1$ \\
\hline
\end{tabular}


treated with $25 \mathrm{~g}$ lysine and $25 \mathrm{~g}$ arginine. $\mathrm{K}^{+}$levels after amino acid infusion $(5.1 \mathrm{mmol} / \mathrm{l}$ in both groups) were lower than in our study. Interestingly, no increase in $\mathrm{K}^{+}$levels was found in patients treated with a mixture of amino acids [10]. Jamar et al. assessed the effects of five amino acid regimens, including a prolonged 10-h infusion with $240 \mathrm{~g}$ amino acids that included $52.8 \mathrm{~g}$ lysine and arginine [33]. They found that, in comparison to the standard 4$\mathrm{h}$ protocol, the protective effect on the kidneys according to dosimetry data was enhanced by the prolonged infusion. The effect on $\mathrm{K}^{+}$levels was, however, not reported.

Several factors may explain the higher levels of $\mathrm{K}^{+}$that we detected in comparison to those reported by Barone et al. [10] and Rolleman et al. [12] when using similar amounts of amino acid, and include the rate of infusion, the timing of blood sampling and the characteristics of the study group. Barone et al. assessed $\mathrm{K}^{+}$levels $2.5 \mathrm{~h}$ after the start of the infusion. The initial infusion rate was higher than the final infusion rate although values were not provided. On the basis of Fig. 1, it is reasonable to expect that the change in $\mathrm{K}^{+}$levels after peptide receptor radionuclide therapy has an initial ascending phase followed by a slower descending phase. Depending on the timing of the peak, early blood withdrawal, such as at $2.5 \mathrm{~h}$, might lead to underestimation of $\mathrm{K}^{+}$levels. Higher infusion rates will probably increase the slope of the ascending phase of the curve with an effect on $\mathrm{K}^{+}$levels depending on the timing of blood sampling. The timing of blood withdrawal as well as the rate of infusion was not specified in the study by Rolleman et al. [12]. Note, however, that Rolleman et al. reported an increase in $\mathrm{K}^{+}$levels from $4.4 \pm$ 0.5 to $5.9 \pm 0.8 \mathrm{mmol} / \mathrm{l}$ after infusion with $75 \mathrm{mg}$ lysine. This value, that is greater than the value we reported, underlines the primary importance of amino acid amounts on $\mathrm{K}^{+}$levels. Finally, we cannot exclude the possibility that differences in $\mathrm{K}^{+}$susceptibility may have been related to the clinical characteristics of the patients.

Another explanation for our findings relates to the potential occurrence of spurious hyperkalaemia [27]. This occurs when blood cells release intracellular $\mathrm{K}^{+}$as a consequence of haemolysis. Haemolysis may take place if too much pressure is applied during blood withdrawal or if processing of the blood sample is delayed. To avoid haemolysis in our study a tourniquet was not applied while drawing blood samples. Moreover, all blood samples were centrifuged within $30 \mathrm{~min}$ of blood withdrawal. Ultimately, the occurrence of haemolysis after peptide receptor radionuclide therapy was definitively excluded by the lack of an increase in lactate dehydrogenase levels at $4 \mathrm{~h}$ as well as at 24 hours after the beginning of infusion (Table 2).

Patients with congestive heart failure (CHF) may have disturbances in $\mathrm{K}^{+}$homeostasis. Decreased $\mathrm{K}^{+}$excretion may occur as a result of reduced glomerular filtration rate, which is quite common in CHF $[23,28,29]$. Reduced $\mathrm{K}^{+}$ excretion is also a side effect of drugs used for the therapy of CHF, namely angiotensin-converting inhibitors, angiotensin-receptor blockers and aldosterone receptor antagonists such as spironolactone, and other potassiumsparing diuretic agents [23, 28-30]. Hyperkalaemia may induce an impairment in cardiac conduction which can result in ventricular fibrillation or asystole [15, 31, 32]. Typical electrocardiogram (ECG) findings in hyperkalaemia include flattened $\mathrm{P}$ waves, prolonged PR interval, wide QRS and tall peaked T waves [15]. No significant changes in ECG were reported by Jamar et al. and Barone et al. in the patients experiencing hyperkalaemia $[10,33]$. For this reason, ECG was not routinely performed in our study. However, fatal cardiac arrhythmias induced by hyperkalaemia may also occur in clinically silent patients [17]. For these reasons, $\mathrm{K}^{+}$levels should be monitored in patients with CHF or in patients prone to cardiac arrhythmias.

Another group of patients in whom $\mathrm{K}^{+}$levels should be monitored carefully is those with NET with clinical risk factors for the development of kidney toxicity undergoing TRT. Patients with hypertension, diabetes, renal morphological abnormalities, history of use of radiological contrast medium and history of chemotherapy with nephrotoxic agents are more likely to develop nephrotoxicity following TRT [4]. In diabetic patients, the combined deficiency of insulinism and aldosterone, which respectively enhance cellular $\mathrm{K}^{+}$uptake and promote $\mathrm{K}^{+}$elimination, is frequently complicated by hyperkalaemia [23, 34]. Other risk factors independently associated with an increased likelihood of hyperkalaemia include reduced glomerular filtration rate, advanced age, increased creatinine levels and increased urea nitrogen level [23, 29, 30].

In a selected group of patients scheduled for two consecutive TRT sessions, $\mathrm{K}^{+}$levels were also determined after furosemide injection during the second therapy cycle. Furosemide is a potent loop diuretic that increases renal excretion of $\mathrm{K}^{+}$by inhibiting the $\mathrm{Na}^{+}-\mathrm{K}^{+}-\mathrm{Cl}^{-}$symporter and is used for the acute therapy of hyperkalaemia [35]. The kaliuresis of $40 \mathrm{mg}$ furosemide injected i.v. peaks $30 \mathrm{~min}$ after injection and returns to baseline by $3.5 \mathrm{~h}$ [20]. Therefore, we investigated whether furosemide would be effective in preventing or limiting the increase in $\mathrm{K}^{+}$serum levels induced by the amino acid infusion. However, the percentage of patients who developed hyperkalaemia was very similar in the two conditions ( $77 \%$ vs. $68 \%)$. The lack of effect of furosemide is probably explained by the fact that the peak concentration of the drug occurs relatively early. Therefore, furosemide only moderately counteracts the effect of amino acid solution occurring after the early part of the infusion. This contrasts with the setting of acute hyperkalaemia where $\mathrm{K}^{+}$values are already at the peak when furosemide is injected. These results indicate that i.v. 
injection of furosemide as performed in this study is not useful for preventing hyperkalaemia in patients with NET undergoing TRT.

There are other potential approaches to reducing nephrotoxicity. Polypeptide-based succinylated gelatin, plasma expander Gelofusine (Braun) and Haemaccel (Hoechst) have been shown to induce low molecular weight proteinuria by reducing the tubular reabsorption process [36, 37]. Plasma expanders also reduce the renal uptake of diagnostic doses of $\left[{ }^{111}\right.$ In-DTPA $\left.{ }^{0}\right]$ octreotide efficiently in animals and in healthy volunteers without showing the typical side effects of amino acid infusion [36, 37]. In rats albumin fragments have been shown to reduce renal uptake of $\left[{ }^{111}\right.$ In-DTPA $\left.{ }^{0}\right]$ octreotide as efficiently as lysine [38]. However, the benefit of plasma expanders and albumin fragments in patients during TRT remains to be assessed. However, our results indicate that these alternatives should be carefully investigated and followed further in order to avoid potentially life-threatening side effects of the amino acid infusion.

Measurement of $\mathrm{K}^{+}$concentrations during TRT has the logistical difficulty of handling radioactive materials. This can be of concern for laboratories that do not regularly handle radioactive materials and have no full access to radiation protection equipment, for example, the central hospital laboratory where the described biochemical and haematological analysis of blood samples were carried out. Our investigations show that the radioactivity levels in all serum samples used for $\mathrm{K}^{+}$analysis (maximum $79 \mathrm{kBq}$ in $400 \mu \mathrm{l})$ are below the threshold $(3 \mathrm{MBq})$ which requires special facilities, and for most samples taken $24 \mathrm{~h}$ after the beginning of the infusion, below the exemption limit $(4 \mathrm{kBq})$. In any case, proper handling and disposal of the blood samples is required at all times. The average time needed for sample preparation and to carry out $\mathrm{K}^{+}$ measurements is approximately $15 \mathrm{~min}$ in total. Based on the determined dose-rates (maximum $0.4 \mathrm{mSv} / \mathrm{h}$ ), it can be concluded that the radiation burden to laboratory personnel which results from the handling of a whole blood sample (e.g. in the case of a medical emergency) is not of concern and neither is the total amount of radioactivity handled $(\leq 1 \mathrm{MBq} /$ per $\mathrm{ml}$; see above). It is important to note that Swiss regulations do not apply to other countries and domestic laws and regulations must be followed.

Amino acid solution has been reported to induce grade I and grade II gastrointestinal toxicity in $10 \%$ to $69 \%$ of patients depending on the type of solution and pattern of infusion $[10,11]$. This effect can be attributed to a pressure decrease in the lower oesophageal sphincter induced by amino acids [10, 39]. In the current study, mild and transient gastrointestinal toxicity was also detected in about one-third of patients. However, some patients experienced nausea or vomiting within $2-3 \mathrm{~min}$ after ${ }^{90}$ Y-DOTATOC injection. Thus, it is possible that both radiopeptide injection as well as amino acid solution may induce mild gastrointestinal symptoms in patients with NET treated with TRT. Similarly, muscle weakness and fatigue, two symptoms that may be related to hyperkalaemia, are frequently reported in patients treated with TRT. Numbness of the lips [40] was reported by one patient with $\mathrm{K}^{+}$levels of $5.4 \mathrm{mmol} / \mathrm{l}$. The effects of amino acid solution on other chemical compounds deserve some comment. In the whole group, mean phosphate levels were significantly reduced $4 \mathrm{~h}$ after the beginning of the infusion compared to baseline. This finding may be attributed to increased anabolism or decreased reabsorption of phosphorus [10]. Decreased chloride levels may be related to transient acidosis [10]. We did not observe any increase in creatinine levels in the whole study group. This finding is consistent with a previous report [10] and further confirms that amino acid solution may be used to reduce nephrotoxicity in patients with NET undergoing TRT [1114, 41, 42]. However, there was a slight but significant increase in urea levels after TRT. This increase can be attributed to the fact that arginine is the amino acid most involved in the urea cycle [10].

\section{Conclusions}

In summary, transitory hyperkalaemia occurred $4 \mathrm{~h}$ after the beginning of the infusion of basic amino acids in up to $77 \%$ of patients with NET undergoing TRT. Severe hyperkalaemia occurred in $19 \%$ of patients, and this could be potentially life threatening with regard to cardiac arrhythmia. Preadministration of furosemide was not effective in preventing the increase in $\mathrm{K}^{+}$levels. $\mathrm{K}^{+}$levels $4 \mathrm{~h}$ after the beginning of the infusion should be monitored in selected patients, such as those with heart disease and those with clinical risk factors for nephrotoxicity. Alternative routes to lower kidney uptake such as plasma expanders should be further investigated.

Acknowledgments We would like to thank Martin Speiser for clinical support, Fausta Chiaverio for administrative support, and Sandra Vomstein and Daniela Biondo for processing the radioactive blood samples.

Conflicts of interest None.

\section{References}

1. Modlin IM, Oberg K, Chung DC, Jensen RT, de Herder WW, Thakker RV, et al. Gastroenteropancreatic neuroendocrine tumours. Lancet Oncol. 2008;9:61-72.

2. Waser B, Tamma ML, Cescato R, Maecke HR, Reubi JC. Highly efficient in vivo agonist-induced internalization of sst 2 receptors in somatostatin target tissues. J Nucl Med. 2009;50:936-41. 
3. Esser JP, Krenning EP, Teunissen JJ, Kooij PP, van Gameren AL, Bakker WH, et al. Comparison of [(177)Lu-DOTA(0),Tyr(3)] octreotate and [(177)Lu-DOTA(0),Tyr(3)]octreotide: which peptide is preferable for PRRT? Eur J Nucl Med Mol Imaging. 2006;33:1346-51.

4. Bodei L, Cremonesi M, Ferrari M, Pacifici M, Grana CM, Bartolomei $\mathrm{M}$, et al. Long-term evaluation of renal toxicity after peptide receptor radionuclide therapy with 90Y-DOTATOC and 177Lu-DOTATATE: the role of associated risk factors. Eur J Nucl Med Mol Imaging. 2008;35:1847-56.

5. Kwekkeboom DJ, Mueller-Brand J, Paganelli G, Anthony LB, Pauwels S, Kvols LK, et al. Overview of results of peptide receptor radionuclide therapy with 3 radiolabeled somatostatin analogs. J Nucl Med. 2005;46:62S-6.

6. Forrer F, Waldherr C, Maecke HR, Mueller-Brand J. Targeted radionuclide therapy with 90Y-DOTATOC in patients with neuroendocrine tumors. Anticancer Res. 2006;26:703-7.

7. de Jong M, Barone R, Krenning E, Bernard B, Melis M, Visser T, et al. Megalin is essential for renal proximal tubule reabsorption of (111)In-DTPA-octreotide. J Nucl Med. 2005;46:1696-700.

8. Mogensen CE, Sølling. Studies on renal tubular protein reabsorption: partial and near complete inhibition by certain amino acids. Scand J Clin Lab Invest. 1977;37:477-86.

9. Behr TM, Goldenberg DM, Becker W. Reducing the renal uptake of radiolabeled antibody fragments and peptides for diagnosis and therapy: present status, future prospects and limitations. Eur J Nucl Med. 1998;25:201-12.

10. Barone R, Pauwels S, De Camps J, Krenning EP, Kvols LK, Smith MC, et al. Metabolic effects of amino acid solutions infused for renal protection during therapy with radiolabelled somatostatin analogues. Nephrol Dial Transplant. 2004;19:2275-81.

11. Bodei L, Cremonesi M, Zoboli S, Grana C, Bartolomei M, Rocca $\mathrm{P}$, et al. Receptor-mediated radionuclide therapy with $90 \mathrm{Y}-$ DOTATOC in association with amino acid infusion: a phase I study. Eur J Nucl Med Mol Imaging. 2003;30:207-16.

12. Rolleman EJ, Valkema R, de Jong M, Kooij PP, Krenning EP. Safe and effective inhibition of renal uptake of radiolabelled octreotide by a combination of lysine and arginine. Eur J Nucl Med Mol Imaging. 2003;30:9-15.

13. Rolleman EJ, Melis M, Valkema R, Boerman OC, Krenning EP, de Jong M. Kidney protection during peptide receptor radionuclide therapy with somatostatin analogues. Eur J Nucl Med Mol Imaging. 2010;37:1018-31.

14. Bernard BF, Krenning EP, Breeman WA, Rolleman EJ, Bakker WH, Visser TJ, et al. D-lysine reduction of indium-111 octreotide and yttrium-90 octreotide renal uptake. J Nucl Med. 1997;38:192933 .

15. Bushinsky DA, Gennari FJ. Life-threatening hyperkalemia induced by arginine. Ann Intern Med. 1978;89:632-4.

16. Dursun I, Sahin M. Difficulties in maintaining potassium homeostasis in patients with heart failure. Clin Cardiol. 2006;29:388-92.

17. Weiner ID, Wingo CS. Hyperkalemia: a potential silent killer. J Am Soc Nephrol. 1998;9:1535-43.

18. Waldherr C, Pless M, Maecke HR, Schumacher T, Crazzolara A, Nitzsche EU, et al. Tumor response and clinical benefit in neuroendocrine tumors after 7.4 GBq (90)Y-DOTATOC. J Nucl Med. 2002;43:610-6.

19. Forrer F, Uusijarvi H, Waldherr C, Cremonesi M, Bernhardt $P$, Mueller-Brand J, et al. A comparison of (111)In-DOTATOC and (111)In-DOTATATE: biodistribution and dosimetry in the same patients with metastatic neuroendocrine tumours. Eur J Nucl Med Mol Imaging. 2004;31:1257-62.

20. Brater DC, Fox WR, Chennavasin P. Electrolyte excretion patterns. Intravenous and oral doses of bumetanide compared to furosemide. J Clin Pharmacol. 1981;21:599-603.
21. Valentin J (ed). P103: The 2007 Recommendations of the International Commission on Radiological Protection. Ann ICRP 2008;37(2-4):1-332.

22. Ponce SP, Jennings AE, Madias NE, Harrington JT. Drug-induced hyperkalemia. Medicine (Baltimore). 1985;64:357-70.

23. Sica DA, Gehr TW, Yancy C. Hyperkalemia, congestive heart failure, and aldosterone receptor antagonism. Congest Heart Fail. 2003;9:224-9.

24. Levinsky NG, Tyson I, Miller RB, Relman AS. The relation between amino acids and potassium in isolated rat muscle. $\mathrm{J}$ Clin Invest. 1962;41:480-7.

25. Dickerman HW, Walker WG. Effect of cationic amino acid infusion on potassium metabolism in vivo. Am J Physiol. 1964;206:403-8.

26. Merimee TJ, Lillicrap DA, Rabinowitz D. Effect of arginine on serum-levels of human growth-hormone. Lancet. 1965;2:668-70.

27. Nyirenda MJ, Tang JI, Padfield PL, Seckl JR. Hyperkalaemia. BMJ. 2009;339:b4114.

28. Obialo CI, Ofili EO, Mirza T. Hyperkalemia in congestive heart failure patients aged 63 to 85 years with subclinical renal disease. Am J Cardiol. 2002;90:663-5.

29. Vereijken TL, Bellersen L, Groenewoud JM, Knubben L, Baltussen L, Kramers C. Risk calculation for hyperkalaemia in heart failure patients. Neth J Med. 2007;65:208-11.

30. Reardon LC, Macpherson DS. Hyperkalemia in outpatients using angiotensin-converting enzyme inhibitors. How much should we worry? Arch Intern Med. 1998;158:26-32.

31. Herman E, Rado J. Fatal hyperkalemic paralysis associated with spironalactone. Observation on a patient with severe renal disease and refractory edema. Arch Neurol. 1966;15:74-7.

32. Desai AS. Hyperkalemia in patients with heart failure: incidence, prevalence, and management. Curr Heart Fail Rep. 2009;6:27280.

33. Jamar F, Barone R, Mathieu I, Walrand S, Labar D, Carlier P, et al. 86Y-DOTA0)-D-Phe1-Tyr3-octreotide (SMT487) - a phase 1 clinical study: pharmacokinetics, biodistribution and renal protective effect of different regimens of amino acid co-infusion. Eur J Nucl Med Mol Imaging. 2003;30:510-8.

34. Cox M, Sterns RH, Singer I. The defense against hyperkalemia: the roles of insulin and aldosterone. $\mathrm{N}$ Engl J Med. 1978;299:525-32.

35. Kim HJ, Han SW. Therapeutic approach to hyperkalemia. Nephron. 2002;92 Suppl 1:33-40.

36. Vegt E, Wetzels JF, Russel FG, Masereeuw R, Boerman OC, van Eerd JE, et al. Renal uptake of radiolabeled octreotide in human subjects is efficiently inhibited by succinylated gelatin. J Nucl Med. 2006;47:432-6.

37. van Eerd JE, Vegt E, Wetzels JF, Russel FG, Masereeuw R, Corstens FH, et al. Gelatin-based plasma expander effectively reduces renal uptake of $111 \mathrm{In}$-octreotide in mice and rats. J Nucl Med. 2006;47:528-33.

38. Vegt E, van Eerd JE, Eek A, Oyen WJ, Wetzels JF, de Jong M, et al. Reducing renal uptake of radiolabeled peptides using albumin fragments. J Nucl Med. 2008;49:1506-11.

39. Gielkens HA, Lamers CB, Masclee AA. Effect of amino acids on lower esophageal sphincter characteristics and gastroesophageal reflux in humans. Dig Dis Sci. 1998;43:840-6.

40. Hertz P, Richardson JA. Arginine-induced hyperkalemia in renal failure patients. Arch Intern Med. 1972;130:778-80.

41. Bodei L, Cremonesi M, Grana C, Rocca P, Bartolomei M, Chinol $\mathrm{M}$, et al. Receptor radionuclide therapy with 90Y-[DOTA]0-Tyr3octreotide (90Y-DOTATOC) in neuroendocrine tumours. Eur J Nucl Med Mol Imaging. 2004;31:1038-46.

42. de Jong M, Rolleman EJ, Bernard BF, Visser TJ, Bakker WH, Breeman WA, et al. Inhibition of renal uptake of indium-111DTPA-octreotide in vivo. J Nucl Med. 1996;37:1388-92. 